\title{
Evaluation of the role of smartphone application for early screening of mental health conditions
}

\author{
Jong-Chul Yang, MD and Jeong-Hee Woo, MD \\ Department of Psychiatry, Chonbuk National University Medical School, Jeonju, Korea
}

Objectives: The participants should be able to recognize that smartphone applications are very useful for early screening of mental health conditions.

Background and aim: Early diagnosis of mental health conditions is very important and many methods are being tried today. The aim of this study is to evaluate the role of smartphone application for self-assessment of psychiatric symptoms about stress, depression, and suicidal ideation.

Materials and Methods: A total of 5,646 respondents were evaluated with three scales (Perceived Stress Scale, PSS, Center for Epidemiologic Study for Depression, CES-D, Scale for Suicidal Ideation, SSI) via smartphone application 'Mindscan'. We analyzed the sociodemographic variables, the levels of three symptoms, and the association between the scores on all three scales.

Results: The mean total scores of PSS, CES-D, and SSI were 24.86, 35.15, and 18.03, respectively. Women showed significantly higher score of PSS, CES-D, and SSI when compared with men. Younger users showed significantly higher score of all three scales when compared with older users. The scores on all three scales were higher than in other studies with off-line surveys. The PSS was positively correlated with CES-D $(r=0.690)$, and with SSI $(r=0.367)$. The CES-D was positively correlated with SSI $(r=0.540)$.

Conclusion: A smartphone application for mental health based on three scales (PSS, CES-D, and SSI) is a relatively useful screening tool compared with off-line general population surveys. The association between the three scales reflects the relationship between the three psychiatric symptoms observed in clinical practice.

\section{References:}

1. Proudfoot J, Parker G, Hadzi PD, Manicavasagar V, Adler E, Whitton A. Community attitudes to the appropriation of mobile phones for monitoring and managing depression, anxiety, and stress. J Med Internet Res 2010;12:64.

2. Hosie A, Vogl G, Carden J, Hoddinott J, Lim S. A way forward: Equipping Australia's mental health system for the next generation. EY and ReachOut Australia;2015..

Key Words: Smartphone, Mental health, Stress, Depression, Suicidal ideation
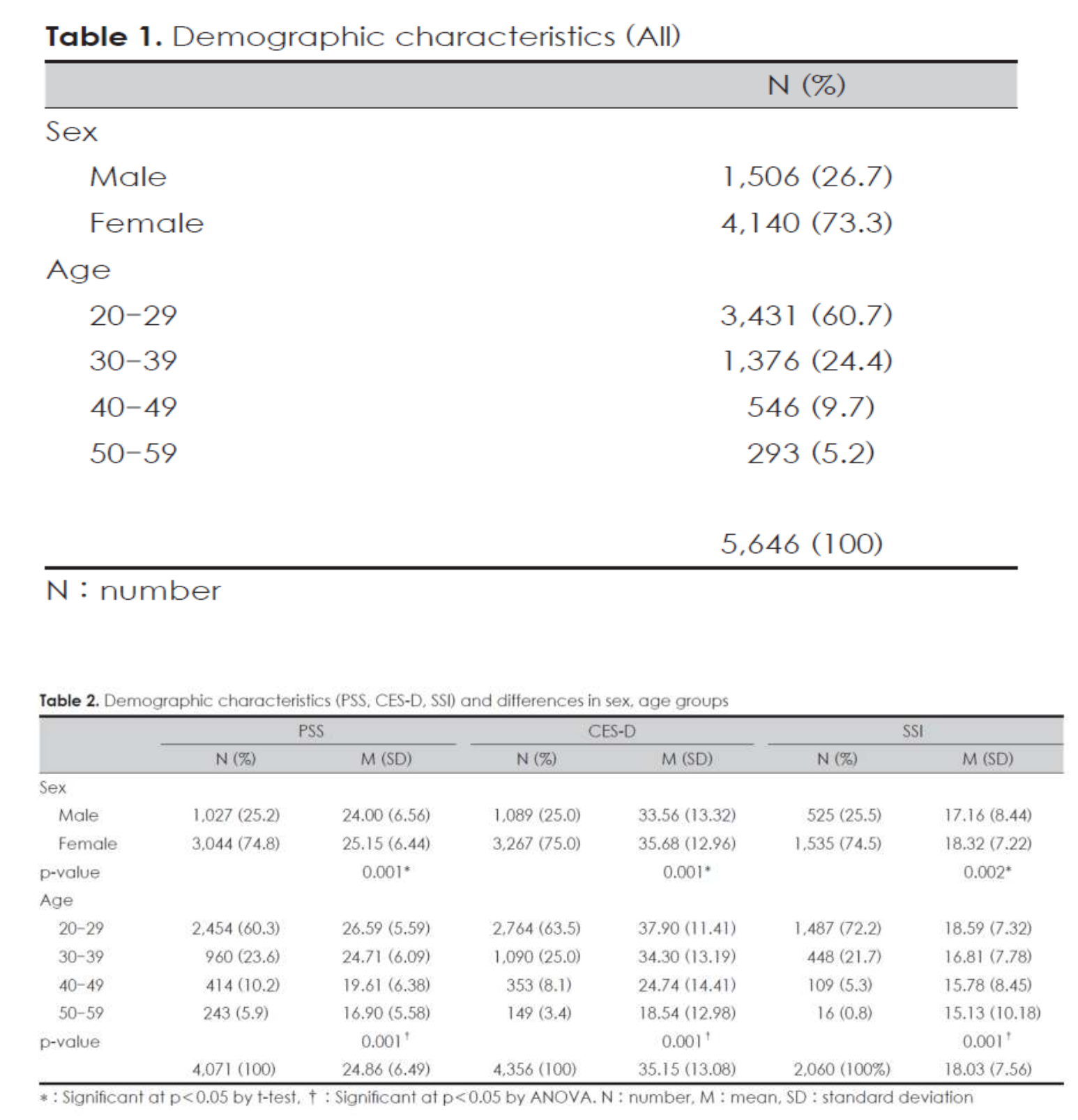

Table 3. Differences between age groups

\begin{tabular}{lclll}
\hline \multicolumn{2}{c}{ AGE } & PSS & CES-D & SSI \\
\hline \multirow{2}{*}{$20-29$} & $30-39$ & $0.001^{*}$ & $0.001^{*}$ & $0.001^{*}$ \\
& $40-49$ & $0.001^{*}$ & $0.001^{*}$ & $0.001^{*}$ \\
& $50-59$ & $0.001^{*}$ & $0.001^{*}$ & 0.399 \\
$30-39$ & $40-49$ & $0.001^{*}$ & $0.001^{*}$ & 1.000 \\
& $50-59$ & $0.001^{*}$ & $0.001^{*}$ & 1.000 \\
$40-49$ & $50-59$ & $0.001^{*}$ & $0.001^{*}$ & 1.000 \\
\hline
\end{tabular}

* : Significant at $\mathrm{p}<0.05$ by Bonferroni post-hoc

Table 4. Demographic characteristics (respond to all scales)

\begin{tabular}{lc}
\hline \multicolumn{1}{l}{ Sex } & $\mathrm{N}(\%)$ \\
Male & $287(21.9)$ \\
Female & $1,021(78.1)$ \\
Age & \\
$20-29$ & $969(74.1)$ \\
$30-39$ & $281(21.5)$ \\
$40-49$ & $55(4.2)$ \\
$50-59$ & $3(0.2)$ \\
\end{tabular}

$\mathrm{N}:$ number

Table 5. Correlations between PSS, CES-D, and SSI

\begin{tabular}{lllll}
\hline & PSS & CES-D & SSI & Age \\
\hline PSS & 1.000 & $0.690^{*}$ & $0.367^{*}$ & $-0.125^{*}$ \\
CES-D & & 1.000 & $0.540^{*}$ & $-0.164^{*}$ \\
SSI & & 1.000 & $-0.166^{*}$ \\
Age & & & & 1.000 \\
\hline
\end{tabular}

* : Significant at $\mathrm{p}<0.01$ by pearson correlation test 